\title{
Canada's physician supply at an all-time high
}

$\mathrm{C}$ anada's physician workforce is bigger than ever, and payments for doctors' services have continued to rise, reaching $\$ 22$ billion in 2012, the Canadian Institute for Health Information (CIHI) reports.

More than 75000 physicians were working in Canada in 2012, almost a 4\% increase over the previous year, according to the CIHI paper Supply, Distribution and Migration of Canadian Physicians, 2012. It also marks the sixth consecutive year that growth in the physician workforce has outpaced population growth.

"The number of physicians is up, which is a good news story, and something that health care planners can use to distribute them appropriately where the greatest needs are," says Walter Feeney, CIHI's health human resources program lead. "One of the highlights of the report is that the number of physicians in rural areas has also increased faster than the rural population over the past five years."

Between 2006 and 2011, the population in rural areas increased by $1.7 \%$, compared to the $10.3 \%$ increase in the number of physicians in rural areas between 2008 and 2012.

"More doctors working in rural areas may be a sign that Canadians' access to physician services in rural areas may be improving," Geoff Ballinger, CIHI's manager of physician information, said in a news release.

CIHI predicts that the physician workforce will continue expanding for some time because more students in Canada are graduating with medical degrees than ever before. The number of medical degrees awarded in Canada increased by a minimum of $3.2 \%$ each year between 2008 and 2012, resulting in an overall increase of $24.7 \%$.

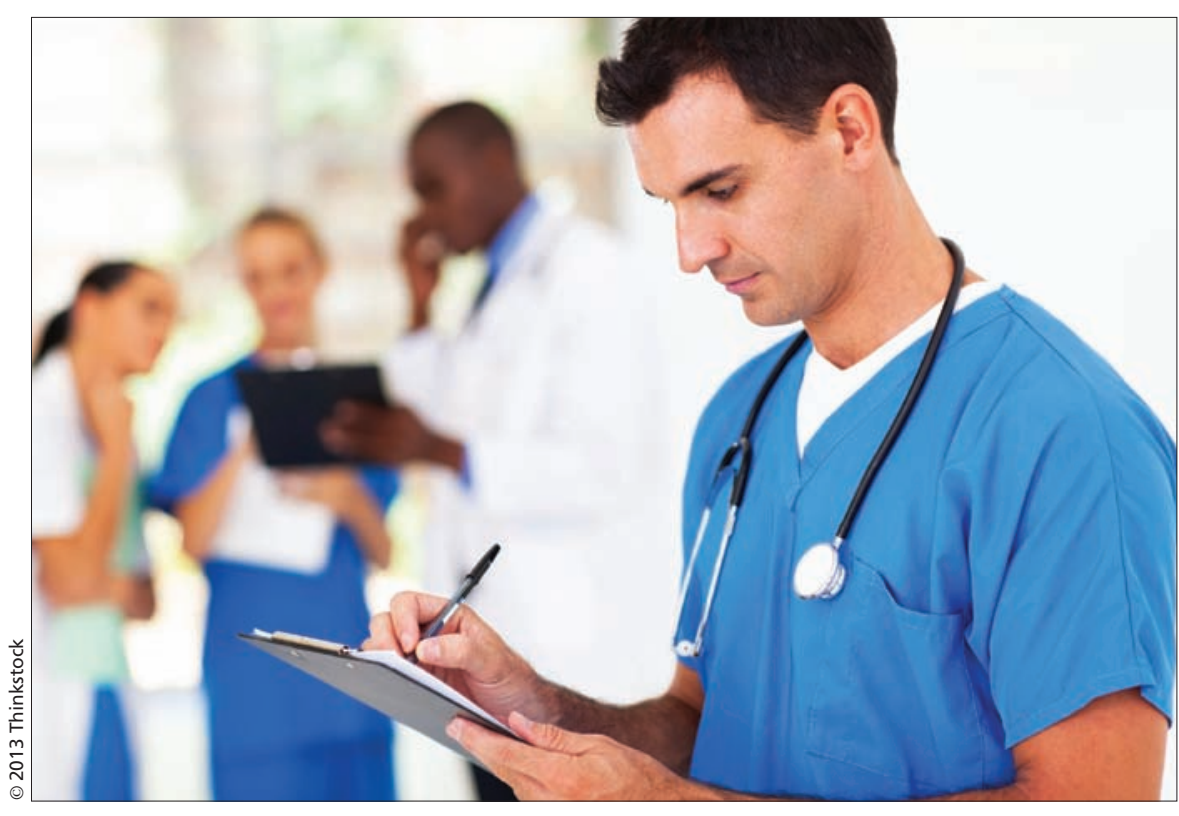

More than 75000 physicians were working in Canada in 2012, almost a $4 \%$ increase over the previous year.

Canada is also gaining more physicians from international migration than it is losing to other countries, and the percentage of physicians working in Canada who trained internationally has increased slightly in recent years, from $23.5 \%$ in 2008 to $24.9 \%$ in 2012 .

"The other side of the story is that payments for services are up as well, as would be expected if there's higher population and more physicians out there," says Feeney.

Overall, government payments for physician services, not adjusting for inflation, increased by $9 \%$ in 2011-12, surpassing increases seen in the previous two years (6\% and $8 \%$, respectively).

Since 1999 , yearly increases in payments for physician services have ranged from a low of $5 \%$ to a high of $10 \%$, Feeney says. "So $9 \%$ is on the higher end of what's happened in the last decade."
Among factors driving overall increases are rising payments for specific fees, increases in alternative payments and the growing population of both physicians and the general public, explains Feeney.

Broken down by specialty, "we're seeing increases across the board ... there's no one [specialty] that's a major driver."

Use of alternatives to fee-for-service payments is also on the rise, with alternative payments making up $29 \%$ of total clinical payments in 2011-12, compared to just $11 \%$ a decade ago. Alternative payments made up the greatest proportion of total clinical payments in Nova Scotia, at $47 \%$, and the smallest in Alberta, at 14\%. - Lauren Vogel, CMAJ

CMAJ 2013. DOI:10.1503/cmaj.109-4614 